\title{
CSI-SF: Psychometric properties of Spanish version of the coping strategies inventory - short form
}

\author{
Jordi Tous-Pallarés ${ }^{1}$, Ivette Margarita Espinoza-Díaz, Susana Lucas-Mangas², \\ Lorena Valdivieso-León ${ }^{2 *}$, and María del Rosario Gómez-Romero ${ }^{3}$ \\ 1 Research Center for Behavior Assessment. Departamento de Psicología. Universidad Rovira i Virgili (Spain) \\ 2 Departamento de Psicología. Universidad de Valladolid (Spain) \\ 3 Escuela Universitaria de la Fe. Universidad Valencia, Valencia (Spain)
}

\begin{abstract}
Título: CSI-SF: Propiedades psicométricas de la versión española del inventario breve de estrategias de afrontamiento.

Resumen: Antecedentes/Objetivo: El estudio establece las propiedade psicométricas de la adaptación española de la versión abreviada del Inventario de Estrategias de Afrontamiento (CSI-SF) publicado por Addison e al. (2007). La prueba utiliza un modelo de dos ejes para clasificar las estrategias de afrontamiento (de compromiso y de evitación) y las categorías objetivas del afrontamiento (centrada en el problema y centrada en la emoción). Método: Participaron 940 personas $(62.87 \%$ mujeres; $37.12 \%$ hom bres) divididas en dos submuestras. Se realizó un análisis factorial exploratorio (AFE) y un análisis factorial confirmatorio (AFC), así mismo la correlación de Pearson y el Alfa de Cronbach para examinar la fiabilidad y validez de la adaptación al español del CSI-SF. Resultados: El análisis de consistencia interna reveló una alta fiabilidad para todas las escalas (EFE = $.890, \mathrm{PFE}=.836 . \mathrm{PFD}=.767, \mathrm{EFD}=.934), \mathrm{y}$ todos los índices de ajuste utilizados para examinar el CSI-SF versión española proporcionaron soporte para su uso como una medida adecuada de las estrategias de afrontamiento del estrés. Discusión/Conclusión: La escala CSI-SF versión española es una prueba que proporciona un diagnóstico rápido y eficiente cuyos factores explican el $62.79 \%$ de la varianza común total de las estrategias de afrontamiento que se emplean frente a la situación de estrés en distintos ámbitos.
\end{abstract}

Palabras clave: CSI-SF. Estrategias de afrontamiento. Estrés. Estudio descriptivo encuesta. Propiedades psicométricas.

\section{Introduction}

Stress management and the choice of the most appropriate strategy for coping with it depend on the emotional and cognitive evaluation of each subject. However, problem solving, cognitive restructuring and the search for social support are the most used strategies (Macías et al., 2013). Due to the large number of stressors to which most human beings are exposed, there is a need to increase efforts in getting to know about the evaluation and intervention in stress coping strategies (Adler, 2017; Guillén et al., 2017; Instituto Nacional de Seguridad e Higiene en el Trabajo -INSHT-, 2017). Thus, depending on the stressful event, they select the coping strategies to use, although there is no consensus about their differential use, nor is their individual or collective use (Rodríguez-Marín \& Neipp-López, 2008).

In this sense, each person can interpret each of the potentially stressful situations in their context according to their particular parameters, and can choose between one and an-

* Correspondence address [Dirección para correspondencia]:

Lorena Valdivieso-León, Phd, Departament of Pychology, University of Valladolid, Campus Duques de Soria, Facultad de Educación, Calle Universidad, s/n, C.P. 42004, Soria (Spain). E-mail: lorena.valdivieso@psi.uva.es (Article received: 29-4-2021, revised: 19-7-2021, accepted: 21-7-2021)
Abstract: Background / Objective: The study establishes the psychometric properties of the Spanish adaptation of the abbreviated version of the Coping Strategies Inventory (CSI-SF) published by Addison et al. (2007). The test uses a two-axis model to classify coping strategies (commitment and avoidance) and objective categories of coping (problem-focused and emotion-focused). Method: 940 people participated $(62.87 \%$ women; $37.12 \%$ men) aged between 18 and 66 years $\left(\bar{x}^{-}=33.2 ; \mathrm{dt}=12.01\right)$. An exploratory factor analysis (EFA) and a confirmatory factor analysis (CFA) were carried out, as well as Pearson's correlation and Cronbach's Alpha to examine the reliability and validity of the Spanish adaptation of the CSI-SF. Results: Internal consistency analysis revealed high reliability for all scales, and all adjustment indexes used to examine the CSI-SF Spanish version provided support for its use as an adequate measure of stress coping strategies. Discussion/Conclusions: The CSI-SF scale Spanish version is a test that provides a quick and efficient diagnosis of the coping strategies used in the face of stress in different settings.

Keywords: CS-SF. Coping strategies. Stress. Descriptive survey study. Psychometric properties. other of their coping strategies. From a preventive and proactive approach, we have always tried to look for those positive aspects, present in each human being, group, organization or community, which promote its quality of life and well-being (Lucas, 2020). Now the World Health Organization and its Working Group on quality of life indicate that quality of life would be established as the search for adequate responses for the promotion of personal and social wellbeing (Conceição, 2019; Valdivieso-León et al., 2020; Sánchez, 2017). Stress coping strategies are a component to promote this quality of life, as a means to achieve it, as contemplated by some studies on dimensions, components and quality of life evaluation indicators which focus on coping strategies and the quality of life of patients with terminal and chronic diseases (Fok et al., 2005; Hyun et al., 2021), and more recently there are some studies that analyze the relationship between stress coping strategies and the quality of life of people during the COVID-19 pandemic situation (Panayiotou et al., 2021; McFadden et al., 2021).

In the principles of community intervention (Sánchez, 2017) it is stated that, in any intervention, the interaction of three components must be taken into account: 1. Intrapersonal: it refers to how people see themselves with respect to their perception of control, self-efficacy, mastery, 
competence to influence on various spheres of their life family, work, organizations...; 2. Interactive: it refers to the idea that people have of their community, the ability to exercise control over their environment, which implies sharing norms and values in a given context, developing a critical consciousness of their own environment, mobilizing resources and making decisions to resolve conflicts; and 3. Behavioral: it refers to specific and direct situations aimed at achieving objectives that favor empowerment -such as, for example, stress coping strategies.

Coping strategies are defined by Lazarus and Folkman (1984) as those behaviors and cognitive skills that people use to cope with internal and environmental demands that are perceived as stressful: when we face stressful life circumstances, we tend to react cognitively or behaviorally to reduce the effects that these experiences may cause on us.

In this sense, it must be considered that problem solving, cognitive restructuring and the search for social support are the most used strategies (Valdivieso-León et al., 2020). Likewise, promoting autonomy and emotional education, creativity and respect for decision-making (personal and collective), responsibility and social commitment (Instituto Nacional de Seguridad y Salud en el Trabajo (INSST) et al., 2019). Similarly, the three types of individual positive psychology interventions acquire great relevance to promote work engagement: intervention in psychological capital -PsyCap-, interventions based on strengths, and interventions aimed at promoting levels of happiness (Bisquerra \& Hernández, 2017; Bohlmeijer et al., 2017; Guillén et al., 2017).

Strategies aimed at adequate and active coping with the problem reduce both stress and its consequences (GonzálezCabanach et al., 2018), and have been associated both with greater emotional well-being (Morales, 2018) and with a decrease in the Psychophysiological symptomatology at the cognitive, emotional, behavioral and anxiety levels (BuelaCasal \& Guillén-Riquelme, 2017).

Given the relevance that stress-coping generates in people's health, it is not surprising that numerous instruments have been developed to assess how people cope with stress in specific situations. One of the most used has been the "Ways of Copping Questionnaire" (WCQ) (Folkman \& Lazarus, 1980). It is a scale that assesses the different coping strategies (or copping) used in standardized situations. Its original version consists of 78 items and uses a Likert scale response format. Its adaptation to Spanish by Sandín \& Chorot (2003) assesses seven basic coping styles: focused on problem solving, negative self-focus, positive reassessment, open emotional expression, avoidance, search for social support, and religion.

Tobin et al. (1989) developed the CSI (Coping Strategy Inventory). It is a 72 -item scale adapted from the WCQ to measure the eight subscales with primary strategies: problem solving, self-criticism, emotional expression, illusions, social support, cognitive restructuring, problem-avoidance and social withdrawal. It incorporates four secondary subscales (which group the primary subscales of the WCQ) and two tertiary ones (engagement and disengagement).

The Spanish version of the CSI was adapted and validated by Cano et al. (2007). The result of this adaptation was a reduced version of 40 items that, according to the authors, showed high levels of internal consistency and adequate convergent validity. However, the secondary and tertiary structures obtained by Tobin et al. (1989) in the original version were not verifiable in the Spanish version.

Addison et al. (2007) used the CSI scale of Tobin et al. (1989) to conduct research on coping strategies in patients with chronic coronary disease and caregivers of chronic patients. As a result of their work, they developed the CSI-SF in English (Addison et al., 2007, 2009) which, despite reducing the number of items to 16 , shows a structure similar to the original CSI scale.

The strategies for coping with stress in the CSI-SF are classified from a $2 \times 2$ matrix (see Table 1). The first axis includes commitment coping strategies, which consist of developing or responding to the stressful situation through behaviors and actions aimed at objectively facing stressors, and avoidance strategies, which consist of trying to limit exposure to stressors to achieve desirable short-term effects.

Two objective categories of coping are positioned on the second axis, one focused on the problem, and the other focused on emotion. Emotion-centered coping emphasizes the regulation of the affective response to the problem, while problem-centered coping emphasizes the management of the stressful situation.

Table 1

CSI-SF Model.

\begin{tabular}{lll} 
Coping strategies & $\begin{array}{l}\text { Orientation to problem } \\
\text { (focused on the problem) }\end{array}$ & $\begin{array}{l}\text { Orientation to emotion } \\
\text { (focused on the emotion) }\end{array}$ \\
\hline $\begin{array}{l}\text { Engagement strategies (Engagement) } \\
\text { Disengagement strategies (Disengagement) }\end{array}$ & F1 (PFE) Problem Focused Engagement & F3 (EFE) Problem Focused Disengagement \\
\hline
\end{tabular}

The use of the new short version of the CSI scale (CSI$\mathrm{SF}$ ) meets the minimum psychometric requirements to measure stress coping in a population of 5302 North Americans, in which it was tested, and it is understood that the methodology and data analysis were the right ones. No Spanish adaptation of the CSI-SF scale of Addison et al. $(2007,2009)$ has been published, as even though Speyer et al.
(2016) carried out the adaptation of the CSI-SF with a population of hemodialysis patients from thirteen countries including Spain $(N=504)$, they could only replicate the CSISF factorial structure with 14 items, in English and in 5 countries: the United States $(N=1,254)$, England $(N=363)$, Canada $(N=247)$, Australia and New Zealand $(N=309)$. As we can see, the CSI-SF is a simple 16-item instrument 
that has been widely used in the English language, therefore its adaptation to the Spanish language is considered important given the benefits that it could provide in research on quality of life and health both at personal and professional level.

In this sense, we consider that the CSI-SF of Addison et al. $(2007,2009)$ presents a series of advantages over others that adequately address coping strategies: a rapid evaluation, a solid model with empirical support, and possibilities for a wide application. Therefore, the present work establishes the psychometric properties and the factorial structure of the abbreviated version in Spanish of the inventory of coping strategies (CSI-SF). The structure and its internal consistency (Cronbach's alpha) will be analyzed using exploratory factor analysis (EFA) and confirmatory factor analysis (CFA) to identify the factors of the scales and in order to see if the factorial structure of the original scale is replicated.

\section{Method}

\section{Participants}

The total number of people who agreed to participate in the study were 940 (62.9\% women; $37.1 \%$ men), aged between 18 and 66 years old $(M=33.2 ; S D=12.01)$. Regarding the scope of dedication: $42.6 \%$ to the commercial sector, $25.2 \%$ are university students, $17.8 \%$ are health professionals, and $14.4 \%$ are teachers. The total sample was randomly divided into two subsamples: one of 400 individuals to perform the exploratory factor analysis (EFA), and another of 540 subjects to perform the confirmatory factor analysis (CFA).

\section{Instruments}

The applied questionnaire consisted of two blocks, the first block containing 4 sociodemographic questions: age, sex, marital status and professional field. The second block contained the 16 items of the original questionnaire (CSI-SF) by Addison et al. $(2007,2009)$ translated into Spanish.

In this sense, the adaptation to Spanish of the CSI-SF assesses the coping strategies from two axes: in a first axis are the strategies focused on commitment or engagement and the avoidance strategies, or disengagement. And in a second axis, the two objective categories of coping are positioned: the solution of the problem (or problem-focused) and the resolution through emotion or (emotion-focused).

Each item of the CSI-SF test was answered by the participants using a 5-point Likert scale. Respondents were asked to rate the general frequency with which they used each coping strategy listed in the survey and to indicate their options as follows: 1. Never, 2. Rarely, 3. Sometimes, 4. Often and 5. Almost always.

The items of the CSI-SF Spanish version test are presented below along with the factor to which each item is associated (see Table 2).

Table 2

List of items and factor loads of the Spanish version of CSI-SF.

\begin{tabular}{|c|c|c|c|c|}
\hline Item & Mean & $S D$ & Factor & Factor load \\
\hline 1.- I make an action plan and I follow it (PFE) & 3.458 & 1.018 & 2 & 0.981 \\
\hline 2.- I look for the silver lining or I try to look on the bright side of things (PFE) & 3.880 & 0.981 & 2 & 0.944 \\
\hline 3.- I try to spend time alone (EFD) & 3.175 & 0.996 & - & - \\
\hline 4.- I hope the problem solves itself (PFD) & 1.962 & 0.958 & 3 & 1 \\
\hline 5.- I try to shut out my emotions (EFE) & 3.158 & 1.056 & 1 & 1 \\
\hline 6.- I try to talk to a friend or family (EFE) & 3.602 & 1.117 & 1 & 0.978 \\
\hline 7.- I try to put the problem out of my mind (PFD) & 3.205 & 1.068 & 3 & 0.83 \\
\hline 8.- I tackle the problem (PFE) & 3.735 & 0.923 & 2 & 1 \\
\hline 9.- I take a step back from the situation and try to put things in perspective (PFE) & 2.967 & 1.065 & 2 & 0.85 \\
\hline 10.- I tend to blame myself or myself (EFD) & 3.092 & 1.076 & 4 & 1 \\
\hline 11.- I let out my feelings to reduce stress (EFE) & 3.023 & 1.079 & 1 & 1 \\
\hline 12.- I hope a miracle occurs (PFD) & 1.678 & 1.082 & 3 & 0.987 \\
\hline 13.- I ask for help or advice from a close friend or family member that I respect (EFE) & 3.525 & 1.097 & 1 & 0.987 \\
\hline 14.- I try not to think about the problem (PFD) & 2.652 & 0.974 & 3 & 0.863 \\
\hline 15.- I tend to criticize myself (EFD) & 3.235 & 1.083 & 4 & 1 \\
\hline 16.- I keep my thoughts and feelings to myself (EFD) & 3.035 & 1.126 & 4 & 1 \\
\hline
\end{tabular}

Note. PFE = Problem Focused Engagement; PFD = Problem Focused Disengagement; EFE = Emotion Focused Engagement; EFD = Emotion Focused Disengagement.

\section{Procedure}

The test was administered through a web platform hosted on the servers of our laboratory. The participants were contacted through companies and institutions that collaborate in other research and transfer projects of our team, who were asked for their support to spread the link through which they could access the platform that hosted the test where they could leave their answers.

The platform had a filter that guaranteed that participants accepted to be part of the study voluntarily, without any type of coercion or economic remuneration. They also stated that they had been informed that the administration of the scale was completely anonymous and governed by the 
Data Protection Law. It must be noted that the research was authorized by the Research and Transfer Ethics Commission of the Rovira i Virgili University (URV) and has the approval of the University of Valladolid, because this research is part of the Teaching Innovation Projects that were accepted on a competitive concurrence by the University of Valladolid (UVa_PID20-21_150).

\section{Data analysis}

Once the sample was obtained, descriptive statistical analyses were carried out (total sample, mean, standard deviation) and the exploratory and confirmatory factor analysis was carried out using the Factor program (Ferrando \& Lorenzo-Seva, 2017) and the SPSS program version 25 for Windows, in order to evaluate the interrelation between the elements of the CSI-SF Spanish version and the internal consistency of the previously mentioned instrument, whose Cronbach's alpha coefficient was 0.865 , a value that translates into good internal consistency, which suggests that the scale is sufficiently reliable in the general Spanish population.

\section{Results}

\section{Exploratory factor analysis (EFA)}

To study the structure of the scale, as mentioned above, the total sample was divided into two parts. With the first part of the sample, the exploratory factor analysis was carried out with the Factor program, the value of the KaiserMeyer-Olkin test was $\mathrm{KMO}=0.76$, which indicates that on the one hand, the random responses present in the dataset were significant, and on the other hand, the correlation matrix was acceptable for the factor analysis. In addition, the parallel analysis was calculated (Horn, 1965) and the analysis indicated that, as can be seen in Table 3, the data are based on four dimensions for the CSI-FS Spanish version, so that for the global scales of the test we chose using these four dimensions subdivided into two general factors: Total Engagement and Total Disengagement.

Regarding the four main dimensions, these were obtained using a method known as "minimum rank factor analysis" (Statistical Inference of Minimum Rank Factor Analysis, MRFA) (Ten Berge \& Kiers, 1991). The MRFA method has the advantage that it distinguishes the explained common variance from the common total variance, which allows the evaluation of the proportion of common variance explained by the analysis, since the initial factorial matrix is obtained on one side (see Table 3 ) and the matrix of correlations between factors that can be seen below in Table 4 .

Table 3

CSI-SF's unrotated factor loading matrix.

\begin{tabular}{lccccc}
\hline Variable & F1 & F2 & F3 & F4 & Communality \\
\hline V1 & 0.313 & 0.226 & 0.034 & 0.283 & 0.230 \\
V2 & 0.431 & 0.498 & -0.232 & 0.057 & 0.491 \\
V3 & 0.181 & 0.183 & 0.469 & 0.056 & 0.290 \\
V4 & 0.263 & -0.047 & 0.653 & -0.488 & 0.735 \\
V5 & 0.719 & -0.095 & -0.25 & -0.077 & 0.595 \\
V6 & 0.753 & -0.305 & -0.276 & -0.005 & 0.736 \\
V7 & 0.512 & 0.289 & 0.008 & -0.168 & 0.374 \\
V8 & 0.391 & 0.387 & -0.324 & 0.270 & 0.480 \\
V9 & 0.409 & 0.267 & 0.312 & -0.082 & 0.343 \\
V10 & 0.211 & -0.349 & 0.682 & 0.322 & 0.736 \\
V11 & 0.749 & -0.133 & -0.205 & -0.014 & 0.621 \\
V12 & 0.330 & -0.106 & 0.579 & -0.195 & 0.494 \\
V13 & 0.650 & -0.303 & -0.152 & -0.064 & 0.542 \\
V14 & 0.438 & 0.239 & 0.249 & -0.156 & 0.335 \\
V15 & 0.230 & -0.181 & 0.670 & 0.432 & 0.722 \\
V16 & -0.189 & 0.392 & 0.695 & 0.083 & 0.679 \\
\hline
\end{tabular}

Table 4

Factor correlation matrix.

\begin{tabular}{lcccc}
\hline Factor & F1 & F2 & F3 & F4 \\
& EFE & PFE & PFD & EFD \\
\hline 1 & 1 & & & \\
2 & -0.058 & 1 & & \\
4 & 0.298 & 0.112 & 1 & \\
4 & -0.155 & 0.543 & 0.023 & 1 \\
\hline
\end{tabular}

Note. PFE $=$ Problem Focused Engagement; PFD = Problem Focused Disengagement; $\mathrm{EFE}=$ Emotion Focused Engagement; EFD = Emotion Focused Disengagement.

Following the same path, the factor analysis carried out with the FACTOR program (Ferrando \& Lorenzo-Seva, 2017) also shows us the indexes for determining factors and the reliability in the internal consistency of the scales of the Spanish version of the CSI-SF scales (see Table 5). In addition to the rotated factorial matrix (see Table 6), which is a linear combination of the first, it does not alter the explained variance and is more easily interpreted.

Table 5

Factor determination and reliability index of the internal consistency of the scales of the Spanish version of the CSI-SF scales.

\begin{tabular}{lcccc}
\hline Factor & Mean & Variance & Standard deviation & ORION \\
\hline EFE & 3.3269 & 2.880 & 0.88456 & .890 \\
PFE & 3.5100 & 1.781 & 0.64226 & .944 \\
PFD & 2.3744 & 1.788 & 0.68938 & .836 \\
EFD & 3.1344 & 1.952 & 0.77994 & .767 \\
\hline
\end{tabular}

Note. PFE = Problem Focused Engagement; PFD = Problem Focused Disengagement; EFE = Emotion Focused Engagement; EFD = Emotion Focused Disengagement; IDF = Factor Determination Index; ORION: Oblique Scores Overall Reliability (Ferrando y Lorenzo-Seva, 2016). 
Table 6

Loading matrix of scores after oblique rotation of factors (Ferrando y Lorenzo-Seva, 2018).

\begin{tabular}{lcccc}
\hline Items & F1 & F2 & F3 & F4 \\
\hline V1 & EFE & PFE & PFD & EFD \\
V2 & - & $\mathbf{0 . 4 0 6}$ & - & - \\
V3 & - & $\mathbf{0 . 6 5 7}$ & - & - \\
V4 & - & - & - & - \\
V5 & - & - & $\mathbf{0 . 8 9 2}$ & - \\
V6 & $\mathbf{0 . 6 8 9}$ & - & - & - \\
V7 & $\mathbf{0 . 8 6 3}$ & - & - & - \\
V8 & - & 0.436 & $\mathbf{0 . 3 0 5}$ & - \\
V9 & - & $\mathbf{0 . 5 8 7}$ & -0.348 & - \\
V10 & - & $\mathbf{0 . 3 9 5}$ & 0.334 & - \\
V11 & - & - & - & $\mathbf{0 . 8 5 9}$ \\
V12 & $\mathbf{0 . 7 2 4}$ & - & - & - \\
V13 & - & - & $\mathbf{0 . 5 5 4}$ & - \\
V14 & $\mathbf{0 . 7 4 6}$ & - & - & - \\
V15 & - & 0.362 & $\mathbf{0 . 3 8 9}$ & - \\
V16 & - & - & - & $\mathbf{0 . 9 1 0}$ \\
\hline
\end{tabular}

Note. Loads less than 0.300 are omitted; PFE $=$ Problem Focused Engagement; PFD = Problem Focused Disengagement; EFE $=$ Emotion Focused Engagement; EFD = Emotion Focused Disengagement.

As can be seen in Table 6, the purpose of the analysis was to obtain a simple solution for the factor for which it was decided to use the Promin method (Ferrando \& Lorenzo-Seva, 2014), since it allowed the rotation of the factorial matrix and simplified the factors.

Furthermore, it should be noted that most rotation methods require items in the analysis that are pure measures to obtain the simplest factorial solution after rotation. However, the assumption that all the elements of a multidimensional questionnaire are pure measures of a single trait is unrealistic (Ferrando \& Lorenzo-Seva, 2018). In this sense, it is considered that Promin can cope with this type of situation better than other rotation methods, for which it has been prioritized over other methods for conducting the analysis (Lloret-Segura et al., 2014).

As already mentioned, the analysis yielded 4 factors that refer to the type of coping that individuals have when facing a situation that causes them stress, assessing whether the focus is on the problem or on the emotion, and if the problem is faced with engagement or disengagement. In this sense, the first factor refers to the emotion focused on engagement (EFE: 5, 6, 11 and 13), the second factor shows us when the problem is focused with engagement (PFE: 1, 2, 8 and 9), the third factor tells us about a problem focused on disengagement (PFD: 4, 7, 12 and 14) and the fourth factor refers to the emotion focused on disengagement (EFD: 10, 15 and 16). Regarding item 3 , as in the CSI-SF version of Speyer et al. (2016), it does not appear loaded in any factor.

From the resulting factorial structure, the global scale was calculated using the items of the 4 factors to group them into two dimensions, that of total engagement (ET: 1, 2, 5, 6, $8,9,11$ and 13) and that of total disengagement (DT: 4, 7, $10,12,14,15$ and 16).
As a general adjustment index, the residual root mean square (RMSR) was calculated. A value of 0.0425 was obtained, which coincides with the threshold proposed by Kelley's (1935) criterion, which allows determining if the fit of the model is acceptable. Finally, the Bentler simplicity S index and loading simplicity (LS index) (Lorenzo-Seva, 2003) had values of 0.93 and 0.40 , respectively, so it can be argued that the values obtained in our study indicate that each element was mainly due to a single dimension, and the overall solution showed a high simplicity factor. There was only one element with a complex structure: item 3 "I try to spend time alone" did not load any factor, as happens in the adaptation of the CSI-SF in the population of hemodialysis patients by Speyer et al. (2016).

\section{Confirmatory Factor Analysis (CFA)}

The confirmatory factor analysis (CFA) was carried out with the Factor program (Ferrando \& Lorenzo-Seva, 2017). It was calculated using unweighted least squares (ULS) in the estimates derived from the correlation matrix and it was proposed that the model should maintain the four correlated factors, as suggested by the previous exploratory factor analysis. Table 4 shows the correlation matrix between the factors, and Table 6 shows the values of the elements that load in each factor.

Various adjustment indexes were examined to assess the adequacy of the model. The comparative adjustment index (CFI) assesses the lack of fit estimated by the non-centrality distribution $\chi^{2}$ of the model compared to the base model. The goodness of fit index (GFI) is an absolute adjustment index, in relation to the relative amount of observed variances and covariances explained by the hypothetical model. $\mathrm{Hu}$ and Bentler (1999) recommend a cutoff value close to 0.95 for the adjustment indexes.

The mean squared error of approximation (RMSEA) is based on the analysis of the residuals and compensates for the effects of the complexity of the model. Hu and Bentler (1999) recommend a cutoff close to 0.06. The values obtained for these indexes in our study were CFI $=0.962$, GFI $=0.985$ and RMSEA $=0.066$ (with a confidence interval between 0.060 and 0.082). Therefore, it was concluded that the data fit the model hypothesis of a reasonably good factor. In addition, the congruence indexes of the factors between the load patterns obtained in the exploratory and confirmatory analyses were $0.944,0.914,0.876$ and 0.934 for each factor, respectively. If this index is between 0.85 and 0.94 , compared to the columns it can be interpreted in a similar way, while values higher than 0.94 mean that the similarity is good (Lorenzo-Seva \& Ten Berge, 2006). 


\section{Analysis of the items}

As the exploratory and confirmatory studies suggest, both samples were representative of the same population. The total sample was used in the item and scale studies. Table 2 shows the mean, standard deviation, and discrimination indexes of the 16 items. It should be taken into account that these discrimination indexes were related to the global scale (which is obtained as the sum of the elements suitably inverted when necessary). As can be seen in the Table, the discriminations were systematically higher than 0.12 , with a maximum of 0.44 . These analyses indicated that all items were associated with each other; therefore, it is assumed that they were combined in a single scale that can be observed in the following analysis.

\section{Scale analysis}

For the analysis of the scale, the scores in the four subscales and the two global scales were calculated. Descriptive statistics are shown in Table 7.

It is interesting to note that the global internal consistency of the CSI-SF Spanish version (Cronbach alpha coefficient $=0.865)$ of the four subscales and the two general scales was lower than the reliability of the factor scores except for the case of the emotion factor on focalized disengagement (EFD), in which case it was the same. On the other hand, the Kolmogorov-Smirnov test evaluated that the distribution of the global scale scores did not differ significantly from a normal distribution.

Table 7

Descriptive statistics for subscales and global scales of the CSF-SF Spanish version.

\begin{tabular}{|c|c|c|c|c|c|c|}
\hline Estadísticos & EFE & PFE & PFD & EFD & ET & DT \\
\hline Number of items & 4 & 4 & 4 & 3 & 8 & 7 \\
\hline Mean & 12.05 & 12.6 & 8.12 & 11.25 & 20.18 & 23.86 \\
\hline Standard deviation & 3.94 & 3.25 & 3.27 & 3.44 & 6.19 & 5.36 \\
\hline Cronbach's Alpha & 0.845 & 0.848 & 0.840 & 0.865 & 0.823 & 0.824 \\
\hline Z Kolmogorov-Smirnov & 1.815 & 2.304 & 2.077 & 1.877 & 1.813 & 2.289 \\
\hline Asymptotic significance & 0.003 & 0.000 & 0.000 & 0.002 & 0.003 & 0.000 \\
\hline
\end{tabular}

Note. PFE = Problem Focused Engagement; PFD = Problem Focused Disengagement; EFE = Emotion Focused Engagement; EFD = Emotion Focused Disengagement.

To allow the interpretation of the practical results in the subscales and global scales, Table 8 shows the percentiles in relation to the raw scores.

Table 8

Percentiles related to the raw scores of the CSI-SF Spanish version.

\begin{tabular}{|c|c|c|c|c|c|c|}
\hline \multirow[b]{2}{*}{ Percentiles } & \multicolumn{6}{|c|}{ Scores } \\
\hline & EFE & PFE & PFD & EFD & ET & DT \\
\hline$\overline{1}$ & 3 & 6 & 1 & 3 & 7 & 14 \\
\hline 5 & 5 & 7 & 3 & 6 & 10 & 16 \\
\hline 10 & 7 & 8 & 4 & 7 & 12 & 17 \\
\hline 15 & 8 & 9 & 5 & 8 & 14 & 18 \\
\hline 20 & 9 & 10 & 5 & 8 & 15 & 19 \\
\hline 25 & 9 & 10 & 6 & 9 & 16 & 20 \\
\hline 30 & 10 & 11 & 6 & 9 & 17 & 20 \\
\hline 35 & 10 & 11 & 7 & 10 & 18 & 21 \\
\hline 40 & 11 & 12 & 7 & 10 & 18 & 22 \\
\hline 45 & 12 & 12 & 8 & 11 & 19 & 23 \\
\hline 50 & 12 & 13 & 8 & 11 & 20 & 24 \\
\hline 55 & 13 & 13 & 9 & 12 & 21 & 25 \\
\hline 60 & 13 & 14 & 9 & 12 & 22 & 26 \\
\hline 65 & 14 & 14 & 9 & 13 & 23 & 26 \\
\hline 70 & 14 & 14 & 10 & 13 & 24 & 27 \\
\hline 75 & 15 & 15 & 10 & 13 & 25 & 28 \\
\hline 80 & 16 & 16 & 11 & 14 & 26 & 29 \\
\hline 85 & 16 & 16 & 12 & 15 & 27 & 30 \\
\hline 90 & 17 & 17 & 12 & 16 & 28 & 31 \\
\hline 95 & 19 & 18 & 13 & 17 & 30 & 32 \\
\hline 99 & 20 & 20 & 16 & 19 & 34 & 35 \\
\hline
\end{tabular}

Note. PFE = Problem Focused Engagement; PFD = Problem Focused Disengagement; $\mathrm{EFE}=$ Emotion Focused Engagement; EFD = Emotion Focused Disengagement.

\section{Discussion / Conclusions}

The results show that the Spanish adaptation of the CSI-SF scale (Addison et al., 2007) has good reliability and validity for the evaluation of the styles or strategies for coping with stress that are proposed in the Lazarus and Folkman model (1984), which is structured in eight primary strategies (problem solving, self-criticism, emotional expression, illusions, social support, cognitive restructuring, problem-avoidance and social withdrawal).

Regarding the CSI of Tobin et al. (1989), it incorporated four secondary and two tertiary subscales (engagement and disengagement); however, the secondary and tertiary structures obtained in the original version were not verifiable in the Spanish version of the CSI that was adapted and validated by Cano et al. (2007).

Addison et al. (2007) developed the English version of the CSI-SF which, despite reducing the number of items to 16 , it shows a similar structure to the original CSI scale (Tobin et al., 1989). Thus, the strategies that make up the coping of stressful situations are organized in a two-way scheme, one related to the stressor's coping strategies (engagement and avoidance strategies) that consist of coping with or trying to limit exposure to stressful stimuli in order to get effects. In a second direction, problem-centered and emotioncentered coping strategies are positioned.

In our Spanish adaptation of the CSI-SF by Addison et al. (2007), item 3 "I try to spend time alone" did not load any factor as shows in the study by Speyer et al. (2016). Never- 
theless, the global scale showed that the reliability of the four subscales with 15 items was as high as in the original scale (Table 9). Moreover, it is also observed how the subscales correlate between pairs (F1- Emotion focused on engagement and F2- Problem focused on engagement) and (F3problem focused on disengagement and F4- emotion focused on disengagement), which suggests that two global subscales could be considered, which collect total engagement (ET) and total disengagement (DT).

On the other hand, it should be noted that, as mentioned before, the Spanish adaptation of the resulting scale consists of 15 items and four factors, which favors its easy administration, allowing a quick and efficient diagnosis of stress coping strategies starting from the validity model recognized in the scientific literature in the studies by Addison et al. (2007, 2009) and Speyer et al. (2016). In this sense, the factor analysis of the CSI-SF Spanish version showed that the questionnaire replicates the four-dimensional structure proposed by the authors of the original scale. In Table 9 it can be observed that the simplicity factor of the general solution was high, and it should also be mentioned that the extracted factors explain $62.79 \%$ of the total common variance as well as the reliability of the global subscales. This suggests that field studies aimed at obtaining scores on each of the four dimensions should use raw facet scores (obtained as the sum of the subscales' item scores).

Table 9

Descriptive statistics of the CSF-SF scales on the Spanish and original version.

\begin{tabular}{|c|c|c|c|c|c|c|c|c|}
\hline \multirow[b]{2}{*}{ Statistics } & \multicolumn{4}{|c|}{ CSI-SF Spanish version } & \multicolumn{4}{|c|}{ CSI-SF original version } \\
\hline & EFE & PFE & PFD & EFD & EFE & PFE & PFD & EFD \\
\hline Number of ítems & 4 & 4 & 4 & 3 & 4 & 4 & 4 & 4 \\
\hline Mean & 12.05 & 12.6 & 8.12 & 11.25 & 13.06 & 15.09 & 11.57 & 11.41 \\
\hline Standard deviation & 3.94 & 3.25 & 3.27 & 3.44 & 2.90 & 2.63 & 2.98 & 2.64 \\
\hline Internal consistency reliability & 0.890 & 0.836 & 0.767 & 0.934 & 0.72 & 0.67 & 0.60 & 0.58 \\
\hline
\end{tabular}

Note. PFE = Problem Focused Engagement; PFD = Problem Focused Disengagement; EFE = Emotion Focused Engagement; EFD = Emotion Focused Disengagement.

Some of the limitations of the present study focus on the fact that the sample of participants could be somewhat limited both in number and in age ranges of the participants. It is considered that future studies should cover a sufficient sample in all age ranges and as future lines of research, work is being done to evaluate the external validity of the instrument, relating its scores to those obtained in burnout and anxiety questionnaires (Buela-Casal \& Guillén-Riquelme, 2017; Vargas et al., 2017).

\section{References}

Addison, C. C., Campbell-Jenkins, B. W., Sarpong, D. F., Kibler, J., Singh, M., Dubbert, P., Wilson, G., Payne, T. J., y Taylor, H. (2007). Psychometric evaluation of a coping strategies inventory short-form (CSI-SF) in the Jackson heart study cohort. International journal of environmental research and public bealth, 4(4), 289-295. https://doi.org/10.3390/ijerph200704040004

Addison, C. C., Campbell-Jenkins, B. W., Sarpong, D. F., Kibler, J., Singh, M., Dubbert, P., Wilson, G., Payne, T. J., y Taylor, H. (2009). Correction: Addison, C.C., et al. Psychometric evaluation of a coping strategies inventory short-form (CSI-SF) in the Jackson heart study cohort. International journal of environmental research and public health, 6, 941-942. https://doi.org/10.3390/ijerph6030941

Adler, A. (2017). Educación positiva: educando para el éxito académico y para la vida plena Positive education: educating for academic success and for a fulfilling life]. Papeles del Psicólogo, 38(1), 50-55. https://doi.org/10.23923/pap.psicol2017.2821

Bisquerra, R., y Hernández, S. (2017). Psicología positiva, educación emocional y el programa aulas felices [Positive psychology, emotional education and the happy classrooms programme]. Papeles del Psicólogo, 38(1), 58-65. https://doi.org/10.23923/pap.psicol2017.2822

Bohlmeijer, E. T., Bolier, L., Lamers, S. M. A., y Westerhof, G. J. (2017). Intervenciones clínicas positivas: ¿por qué son importantes y cómo funcionan? [Positive clinical interventions: Why are they important and how do they work?]. Papeles del Psicólogo, 38(1), 34-41. https://doi.org/10.23923/pap.psicol2017.2819
Financing: This research has received financial support from the University of Valladolid within the Call for Teaching Innovation Projects 2020-2021.

Declaration of conflict of interest. All authors certify that this manuscript has not been published in whole or in part, nor is it being considered for publication elsewhere. The authors have no conflicts of interest to declare. Declaration of interests: none.

Buela-Casal, G., y Guillén-Riquelme, A. (2017). Short form of the Spanish adaptation of the State-Trait Anxiety Inventory. International Journal of Clinical and Health Psychology, 17(3), 261-268. https://doi.org/10.1016/j.ijchp.2017.07.003

Cano, F. J., Rodríguez, L., y García, J. (2007). Spanish version of the Coping Strategies Inventory. Actas Españolas De Psiquiatría, 35(1), 29-39.

Conceição, P. (2019). Informe sobre el Desarrollo Humano 2019: Más allá del ingreso, más allá de los promedios, más allá del presente: Desigualdades del desarrollo bumano en el siglo XXI. Programa de Naciones Unidades para el Desarrollo [Human Development Report 2019: Beyond income, beyond averages, beyond the present: Human development inequalities in the 21 st century. United Nations Development Programme]. http://www.hdr.undp.org/sites/default/files/hdr_2019_es.pdf

Ferrando, P. J., y Lorenzo-Seva, U. (2014). El análisis factorial exploratorio de los ítems: algunas consideraciones adicionales [Exploratory Item Factor Analysis: some additional considerations]. Anales De Psicología 30(3), 1170-1175. http://dx.doi.org/10.6018/analesps.30.3.199991

Ferrando, P. J., y Lorenzo-Seva, U. (2017). Program FACTOR at 10: Origins, development and future directions Psicothema, 29(2), 236-240. http://dx.doi.org/10.7334/psicothema2016.304

Ferrando, P. J., y Lorenzo-Seva, U. (2018). Assessing the quality and appropriateness of factor solutions and factor score estimates in exploratory item factor analysis. Educational and Psychological Measurement, 78(5), 762780. https://doi.org/10.1177/0013164417719308 
Fok, S. K., Chair, S. Y., y Lopez, V. (2005). Sense of coherence, coping and quality of life following a critical illness. Journal of advanced nursing, 49(2), 173-181.

Folkman, S., y Lazarus, R.S. (1980). An analysis of coping in a middleaged community simple. Journal of health social behaviour, 21, 219-239.

González-Cabanach, R., Souto-Gestal, A., González-Doniz, L., y FrancoTaboada, V. (2018). Perfiles de afrontamiento y estrés académico en estudiantes universitarios [Profiles of coping and academic stress among university students]. Revista de Investigación Educativa, 36(2), 421-433. https://doi.org/10.6018/rie.36.2.290901

Guillén, V., Botella, C., y Baños, R. (2017). Psicología clínica positiva y tecnologías positivas [Positive clinical psychology and positive technologies]. Papeles del Psicólogo, 38(1), 19-25. https://doi.org/10.23923/pap.psicol2017.2817

Horn, J. L. (1965). A rationale and test for the number of factors in a factor analysis. Psychometrika, 30, 179-185. https://doi.org/10.1007/BF02289447

Hu, L., y Bentler, P. M. (1999). Cutoff criteria for fit indexes in covariance structure analysis: Conventional criteria versus new alternatives. Structural Equation Modeling: A Multidisciplinary Journal, 6(1), 1-55. http://dx.doi.org/10.1080/10705519909540118

Hyun, J. W., Song, H. J., y Choi, J. H. (2021). Associations of Illness Symptoms, Perception of Illness, and Coping with Quality of Life of Thyroid Cancer Patients after Thyroidectomy. Journal of Korean Biological Nursing Science, 23(1), 83-90. http://dx.doi.org/10.7586/jkbns.2021.23.1.83

Instituto Nacional de Seguridad e Higiene en el Trabajo (INSHT). (2017). Some guidelines for assessing psychosocial risk factors.

Instituto Nacional de Seguridad y Salud en el Trabajo (INSST), O. A., y M. P. (2019). ERGA-PT Primaria Transversal. (Vol. 52, $1^{\circ}$ semestre).

Kelley, T. L. (1935). Essential Traits of Mental Life, Harvard Studies in Education (Vol. 26). Harvard University Press.

Lazarus, R. S., y Folkman, S. (1984). Stress, appraisal, and coping. Springer.

Lorenzo-Seva, U. (2003). A factor simplicity index. Psychometrika, 68, 49-60. https://doi.org/10.1007/BF02296652

Lorenzo-Seva, U., y Ten Berge, J. M. F. (2006). Tucker's congruence coefficient as a meaningful index of factor similarity. Methodology: European Journal of Research Methods for the Behavioral and Social Sciences, 2(2), 57-64. https://doi.org/10.1027/1614-2241.2.2.57

Lloret-Segura, S., Ferreres-Traver, A., Hernández-Baeza, A., y TomásMarco, I. (2014). El Análisis Factorial Exploratorio de los Items: una guía práctica, revisada y actualizada [Exploratory Item Factor Analysis: a practical guide revised and updated]. Anales de Psicología, 30(3), 11511169. https://dx.doi.org/10.6018/analesps.30.3.199361

Lucas, S. (2020). El desarrollo de proyectos emprendedores de aprendizaje-servicio socialmente responsable (The development of socially responsible service-learning entrepreneurial projects]. Dykinson. Manuscrito entregado para la publicación.

Macías, M. A., Madariaga, C., Valle, M., y Zambrano, J. (2013). Individual and family copying strategies when facing psychological stress situations. Psicología desde el Caribe, 30(1), 123-145.
McFadden, P., Ross, J., Moriarty, J., Mallett, J., Schroder, H., Ravalier, J., y Gillen, P. (2021). The role of coping in the wellbeing and work-related quality of life of UK health and social care workers during COVID-19. International Journal of Environmental Research and Public Health, 18(2), 815821. https://doi.org/10.3390/ijerph18020815

Morales, F. M. (2018). Estrategias de afrontamiento en una muestra de estudiantes universitarios [Coping strategies in a sample of university students]. Revista INFAD de Psicología, 2(1), 289-294. https://doi.org/10.17060/ijodaep.2018.n1.v2.1228

Panayiotou, G., Panteli, M., y Leonidou, C. (2021). Coping with the invisible enemy: The role of emotion regulation and awareness in quality of life during the COVID-19 pandemic. Journal of Contextual Behavioral Science,19(1) 17-27. https://doi.org/10.3390/ijerph18020815 https://doi.org/10.3390/ijerph18020815

Rodríguez-Marín, J., y Neipp-López, M. C. (2008) Manual de psicología social de la salud (Handbook of the social psychology of health]. Síntesis.

Sánchez, A. (2017). Empoderamiento, liberación y desarrollo humano [Empowerment, liberation and human development]. Psychosocial Intervention, 26(3), 155-163. https://doi.org/10.1016/j.psi.2017.05.001

Sandín, B., y Chorot, P. (2003). Cuestionario de afrontamiento del estrés (CAE): desarrollo y validación preliminar [The Coping Strategies Questionnaire: Development and preliminary vaUdation]. Revista de Psicopato$\begin{array}{llll}\text { logía } & y & \text { Psicología Clínica, } & \text { 8(1), }\end{array}$ https://doi.org/10.5944/rppc.vol.8.num.1.2003.3941

Speyer, E., Morgenster, H., Hayashino, Y., Kerr, P. G., Rayner, H., Robinson, B. M., y Pisoni, R. L. (2016). Reliability and validity of the coping strategy inventory-short form applied to hemodialysis patients in 13 countries: Results from the Dialysis Outcomes and Practice Patterns Study (DOPPS). Journal of Psychosomatic Research, 91, 12-19. https://doi.org/10.1016/j.jpsychores.2016.08.015

Ten Berge, J. M. F., y Kiers, H. A. L. (1991). A numerical approach to the exact and the approximate minimum rank of a covariance matrix. Psychometrika, 56, 309-315. https://doi.org/10.1007/BF02294464

Tobin, D. L., Holroyd, K. A., Reynolds, R. V., y Wigal, J. K. (1989). The hierarchical factor structure of the coping strategies inventory. Cognitive Therapy and Research, 13(4), 343-361. https://doi.org/10.1007/BF01173478

Valdivieso-León, L., Lucas-Mangas, S., Tous-Pallarés, J., y Espinoza-Díaz, I. M. (2020). Estrategias de afrontamiento del estrés académico universitario: educación infantil-primaria [Coping strategies for academic stress in undergraduate students: early childhood and primary education]. Educación XX1, 23(2), 165-186. https://doi.org/10.5944/educXX1.25651

Vargas, L. D., Niño, C. L., y Acosta, J. Y. (2017). Estrategias que modulan el síndrome de Burnout en enfermeros (as): una revisión bibliográfica [Strategies that modulate the Burnout syndrome in nurses: a bibliographic review]. Revista Ciencia y Cuidado, 14(1), 111-131. https://doi.org/10.22463/17949831.810 